\title{
Dura Máter: um espetáculo feminista
}

\author{
GOMES, Bruna, Dura Máter, $1^{a}$ edição, Teatro de Arena, Porto Alegre-RS, Al- \\ málgama, 2019, 33 min. ${ }^{1}$
}

\section{Caroline Leszczynski Nunes Lauermann ${ }^{2}$}

A expressão Dura Máter vem do latim e refere-se a mais externa e espessa meninge cerebral, responsável por proteger o cérebro de impactos e ainda faz a relação direta do sistema nervoso com o cardíaco remetendo a relação racional e emotiva que percorre o cotidiano feminino. [...] Em meio ao atual cenário político e social, é cada vez mais urgente e necessário a expressão artística enquanto instrumento de luta social. O grupo Al-málgama de dança tribal, composto exclusivamente por mulheres, traz neste espetáculo além de toda sua técnica e preparo artístico, a luta pela equidade de gênero. (DURA MÁTER, 2019a).

A dança como "movimento em um corpo que abriga conceitos e conteúdos e que se relaciona com um espaço físico" (INFANTE, 2011, p.26), nos instiga a refletir sobre o corpo. Que conceitos nossos corpos abrigam? A que conteúdos estão relacionados? Quais são os espaços sociais que os corpos femininos ocupam? O espetáculo Dura Máter promove a problematização destas e de outras tantas questões por meio de um fazer artístico na dança.

Dura Máter, um show de dança tribal que foi apresentado nos dias 11, 12 e 13 de dezembro de 2019, no Teatro de Arena, na cidade de Porto Alegre/ RS, teve como premissa tecer uma narrativa feminista por meio da dança trazendo "à tona aquilo que atinge e machuca mulheres diariamente na sociedade" (DURA MÁTER, 2019b).

1 A apresentação está disponível em: https://www.youtube.com/watch?v=Cyc2-

7hSRQ8\&feature=youtu.be\&fbclid=IwAR1I5rIGuBytGkNTnt59hdgtXqYkC6nAOdTbCZ2hK_vr2PKJA0q6st1m ngc

2 Mestranda em Educação -Unisinos, especialista em Arte e Educação, Licenciada em Artes Visuais, professora de Artes na Rede Muncipal de Educação de Porto Alegre. Carollesz@hotmail.com 
Idealizado e dirigido por Bruna Gomes, contou com iluminação de Leandro Gass; som de Haik Yermina; figurino de Loraine Santos; maquiagem de Bárbara Degrandi; texto de Amandah Necchi e com um elenco composto por 15 bailarinas: Amandah Necchi, Bruna Gomes, Bárbara Degrandi, Bárbara Kale, Claudinha Goulart, Elisa Moraes, Fabiane Nacad, Fernanda Almeida, Laura Schultze, Lisiane Peixoto, Loraine Santos, Paula Trombetta, Samira D’ornelles, Sibele Faller e Taís Schneider.

Figura 1- Cenas do espetáculo Dura Máter

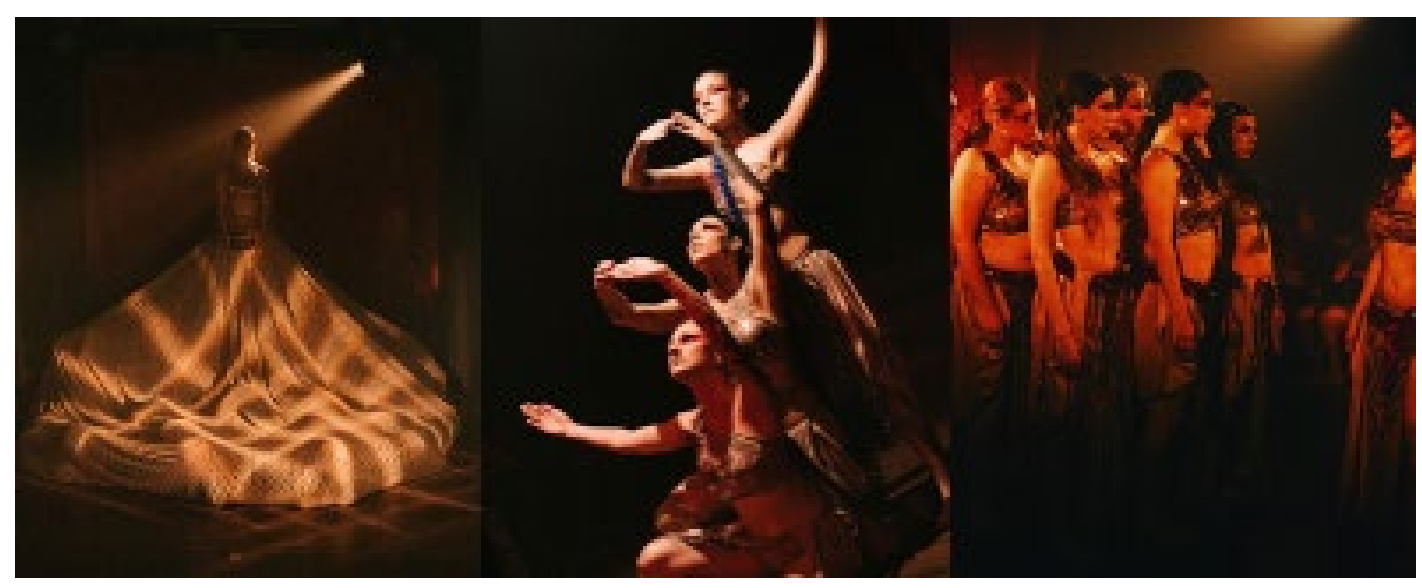

Fonte: BALDO, Lau (2019)

O espetáculo obteve nove indicações ao Prêmio Açorianos em dança que é uma premiação, organizada pela Secretária Municipal de Cultura de Porto Alegre, conhecida e prestigiada no meio artístico e cultural da cidade. As categorias e as indicações foram de espetáculo do ano; direção, para Bruna Gomes; bailarina, para Taís Schneider; coreografia, para Bruna Gomes; cenografia, para Al-málgama; iluminação, para Leandro Gass; figurino, para Loraine Santos; produção e destaque na categoria Dança do Ventre para Al-málgama. A cerimônia de premiação aconteceria no dia 31 de março de 2020, no Teatro Renascença, porém, devido à pandemia Covid-19 e às medidas de isolamento social que precisaram ser adotadas, a cerimônia não foi realizada e até o momento, a nova data ainda não foi divulgada.

Bruna Gomes, criadora e diretora do grupo Al-málgama, iniciou sua atuação no cenário da dança, no ano 2000, mas passou a dedicar seus estudos, desde 2005, exclusivamente ao estilo de dança Tribal Fusion, sendo uma das precursoras desse estilo na cidade, tem obtido positiva repercussão, no meio artístico, com os trabalhos apresentados, tornando-se uma referência bem-conceituada pro estilo tribal. 
Importante destacar que embora seja um estilo de dança que possui referências convergentes à Dança do Ventre, o Tribal Fusion agregou ao longo de sua consolidação, a influência de vários estilos de danças, o que dá a esse estilo, uma característica contemporânea marcada pela hibridação ${ }^{3}$ que, inclusive, agrega a possibilidade para criação e interpretação cênica.

A ideia do corpo como enunciador de pensamentos, uma perspectiva abordada por Setenta (2008), contribui para o entendimento da potência que pode estar contida em uma composição artística de dança. O espetáculo apresentado por Al-málgama, buscou proporcionar, por meio de vários elementos utilizados, a composição de uma obra que pudesse propiciar experiências sensoriais e estéticas ${ }^{4}$, além de, alinhado à ideia da dança como possibilidade para significação, comunicar o discurso da temática do feminismo a que se propôs.
[...] a sociedade patriarcal também executa esse papel de Dura Máter, perpetuando sob seus filhos e filhas o machismo que foi, durante muito tempo, imposto sobre ela. Em resumo o espetáculo trata sobre como a consciência da mulher em relação ao meio social faz com que seja possível vislumbrar a busca por equidade. (DURA MÁTER, 2019a).

Inserido nessa busca por consciência, o espetáculo expõe, justamente, a falta dessa desejada equidade, promovendo, assim, maior comoção no público feminino que, afinal, cotidianamente sente na pele o que é viver numa sociedade sexista.

A composição do espetáculo é constituída por oito coreografias: I. Caixa de Pandora, II. A louca, III. A bailarina, IV. Distorção, V. As mãos, VI. Cabelos, VII. Depressão e VIII. Reverso. Cada uma delas contém uma narrativa que também foi abordada por meio das poesias, escritas por Amandah Necchi, contidas em um livreto recebido na bilheteria do teatro.

A primeira parte apresenta a mulher numa analogia entre a capacidade de ser mãe/ gerar, e a origem do mal. Há envolvido um sentimento de um papel de perpetuação, tanto da espécie quanto do mal, que expressa uma hipnótica reprodutibilidade numa atmosfera que envolve mitologia e mistério, mas a referência à Pandora cumpre a função

3 Sobre Tribal Fusion e hibridação ver: Joline Teixeira Araújo Andrade, 2011.

4 Para Dewey (2010), o estético refere-se à experiência como apreciação, percepção e deleite. Ele formula a ideia do estético como proporcionador do enriquecimento de experiências. 
de questionar que o feminino não é uma dádiva ou maldição divina, senão toda problematização seria em vão, visto que só faz sentido problematizar a questão do feminino enquanto produto social, quando há a consciência das estruturas que envolvem a modelagem das nossas mentes e corpos. Essa problematização é indicada na coreografia subsequente onde algumas bailarinas/mulheres começam a demonstrar certa insatisfação daquela hipnótica repetição, mas ainda assim, dentre os momentos de exaustão, elas seguem.

"A bailarina" traz a imposição de um corpo gracioso, desejado que deixa de ser seu, que deve ser entregue, submisso e aceitar um papel que lhe é imposto. E é com tantas imposições que chega-se à “Distorção”, porque são tantas características a serem desejadas que o desejo torna-se uma busca doentia que violenta e deforma permanentemente aquilo que se é. Mas “As mãos” logo após, demonstram que a violência não é apenas simbólica ${ }^{5}$, e ter de lidar com o sofrimento causado pelo abuso sexual é a realidade de um número assustador de mulheres, em um país em que infelizmente a culpabilização da vítima ainda é assunto recorrente, mesmo diante dos dados que demonstram que a maioria das vítimas de violência sexual possuem até 13 anos de idade 6 . A coreografia intitulada "Cabelos" evoca uma conexão entre as bailarinas/mulheres que estão unidas pelos cabelos. O cuidado que elas demonstram ter umas com as outras em alguns momentos, remete a um sentimento de sororidade ${ }^{7}$, porém estes "cabelos" também aprisionam e exercem a função de manter as bailarinas/mulheres sob o torpor da manutenção de certo controle exercido sobre elas.

A penúltima coreografia faz com que o público perceba que o que ali está sendo dito pode ser mais do que uma alusão a uma situação de tristeza ou desânimo passageiro. "Depressão" imerge o público em uma sufocante condição que demonstra ser atordoante, imobilizadora e desesperadora ${ }^{8}$. O final incute uma certa sensação de Déjà vu porque há elementos semelhantes da "Caixa de Pandora”. Parece ser o perpétuo retorno que nos lembra o Ouroboros, mas ali onde tudo pode estar se repetindo, também aparenta ser diferente, talvez "Reverso".

5 Violência simbólica é um conceito elaborado por Pierre Bourdieu que diz respeito a uma forma de violência que não envolve agressão física, mas causa danos morais e psicológicos.

6 De acordo com reportagem de Paulo Gomes veiculado na Folha de São Paulo em 10 set. 2019.

7 "Do latim soror (irmã), a palavra designa uma espécie de solidariedade específica entre mulheres". (LEAL, Tatiane).

8 Segundo Tassinari (2020), depressão "é diferente da tristeza", é uma doença que precisa ser tratada com o acompanhamento de especialistas. 
O dizer na dança, que apresenta a ideia da dança como linguagem, é denominado por Setenta (2008) como um fazer-dizer, que é dito pelo corpo que dança. As bailarinas de Dura Máter não descrevem algo que acontece. Imbuídas no fazer-dizer, dançam o que sentem e sentem o que dançam, assim demonstram que mais do que estarem se referindo a uma temática, submergem nela. Talvez seja por isso o nó na garganta relatado por alguns expectadores. Elas não dizem nada da boca pra fora. Cada gesto é sentido, intenso e prenhe de significados. Ver, sentir, perceber mulheres que no fazer da dança, estão dizendo como os corpos femininos estão a se fazer e serem feitos na sociedade. A produção do espetáculo, assim, alcança a manifestação da "tradução e transformação de ideias em movimentos" (SETENTA, 2008, p.51), demonstrando o primor artístico para a consumação de uma experiência estética completa.

\section{Referências}

ANDRADE, Joline Teixeira Araújo. Processos de hibridazação na dança tribal: Estratégias de transgressões em tempos de globalização contra hegemônica. $34 \mathrm{f}$. Trabalho de Conclusão do Curso de Especialização (Especialista em Estudos Contemporâneos sobre Dança)- Programa De Pós-Graduação Especialização em Estudos Contemporâneos sobre Dança, Universidade Federal Da Bahia (UFBA), Salvador, 2011.

BALDO, Lau. Dura Máter. 2019. Disponível em:

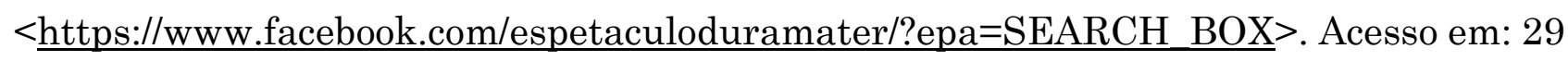
mai. 2020.

DEWEY, John. Arte como experiência. Tradução: Vera Ribeiro- São Paulo: Martins Fontes, 2010.

DURA MÁTER. Dura Máter. 08 out. 2019. Disponível em: <https://www.facebook.com/espetaculoduramater/photos/a.134343411284196/13434338 7950865/?type=3\&theater $>$. Acesso em: 29 jun.2020a.

DURA MÁTER. Dura Máter. 24 maio 2020. Disponível em: <https://www.facebook.com/espetaculoduramater/photos/a.134343411284196/27140770 4244432/?type=3\&theater $>$. Acesso em: 27 jun. $2020 \mathrm{~b}$.

GOMES, Paulo. Brasil registra mais de 180 estupros por dia; número é o maior desde 2009. Folha de São Paulo, São Paulo, 10 set. 2019. Disponível em: 
$<$ https://www1.folha.uol.com.br/cotidiano/2019/09/brasil-registra-mais-de-180estupros-por-dia-numero-e-o-maior-desde-2009.shtml>. Acesso em: 29 jun. 2020.

INFANTE, Rocio. Fundamentos da dança: "corpo - movimento - dança". Paraná:

Editora UNICENTRO, 2011.

LEAL, Tatiane. A invenção da sororidade: sentimentos morais, feminismo e mídia. 216 f. Tese (Doutorado em Comunicação)- Programa de Pós-Graduação em Comunicação e Cultura, Universidade Federal do Rio de Janeiro (UFRJ), Rio de Janeiro, 2019.

SETENTA, JS. O fazer-dizer do corpo: dança e performatividade. Salvador: EDUFBA, 2008.

TASSINARI, Monique. Você sabe qual a diferença entre tristeza e depressão? 30 jun. 2020 .

Disponível em:

$<$ https://www.facebook.com/psicologamonique/photos/a.875484909202463/3039248389 492760/?type=3\&theater $>$. Acesso em: 30 jun. 2020.

Recebido em janeiro de 2021.

março de 2021.

Aprovado em 